\title{
The efficacy of hysteroscopy in diagnosis and treatment of endometrial pathology
}

\author{
Andreia Alexandra Rocha Antunes
}

Received: 13 February 2011 /Accepted: 8 April 2011 /Published online: 7 May 2011

(C) Springer-Verlag 2011

\begin{abstract}
Hysteroscopy has become the first choice approach for patients with suspicion for intrauterine lesions. The one-stop approach in which diagnosis and hysteroscopic treatment is performed in one session has been described as being highly appreciated by the patient, has a low risk profile, and is a costefficient approach. This study addresses the value of hysteroscopy on diagnostic accuracy and its effectiveness to the onestop therapeutic approach. This is a prospective study of patients admitted in the ambulatory surgery unit of the Sto. André-Leiria Hospital (Portugal) from February 2005 to February 2008 for a one-stop diagnostic and therapeutic approach. Patient selection was done on transvaginal ultrasound findings or on clinical pathology. Depending on the transvaginal ultrasound report and the clinical data, the instrumentation and analgesia for the one-stop approach was defined. The average age was 54 years (range24-87 years). The majority of patients $(96.2 \%)$ presented with a transvaginal ultrasonographic lesion. The hysteroscopic evaluation characterized the hysteroscopic findings in two groups: the "uterine cavity lesions" (endometrial and cervical polyps, myomas, malignant smooth muscle tumor, placenta or first trimester debris, bone, adhesions or septum, lost IUD, or no lesion) and "the endometrial characterization" (which include functional atrophic or thin endometrium, dysfunctional, endometritis, cystic atrophy, hyperplasia, polypoid, and carcinoma). We concluded that the ambulatory performance of direct visualization of uterine cavity by hysteroscopy guarantees a high diagnostic accuracy, allowing the simultaneous accomplishment of biopsies and surgical treatment of the visualized lesions.
\end{abstract}

\section{A. A. R. Antunes $(\bowtie)$}

Hospital de Santo André, S.A,

Rua das Olhalvas-Pousos,

2410-197 Leiria, Portugal

e-mail: Andreia.antunes@sapo.pt
Keywords Hysteroscopy · Histology · Endometrial pathology $\cdot$ Uterine lesions

\section{Background}

Since the beginning we felt that the certification of each exam should be a priority, so we decided to biopsy every endometrium and every lesion, to compare the diagnostic accuracy of hysteroscopy with the pathologic exam. To prove the efficacy of this technique, we decided to include in this prospective study only the procedures where hysteroscopy diagnosis and treatment were performed in one single session. Diagnostic accuracy and effectiveness of hysteroscopy were evaluated.

\section{Subjects and methods}

A prospective study was carried out at the day surgery unit of the gynecology department from Santo André Hospital, which is a public care unit in Leiria (Portugal), from February 2005 to February 2008. All patients referred with either abnormal ultrasound findings, abnormal uterine bleeding, infertility, abnormal cells in cervix cytology, or cervical polyps were admitted to the one-stop procedure in the outpatient department after informed consent of the patient. Hysteroscopic examination and hysteroscopic surgery or biopsies were performed to every patient, and pathological investigations were carried out. Postmenopausal patients were given $400 \mathrm{mg}$ transvaginal mysoprostol the night before hysteroscopy.

Hysteroscopy was performed using either rigid panoramic type $30^{\circ}$ telescopes of 2 and $3 \mathrm{~mm}$ with continuous irrigation sheath with five French working channels or the 
4-mm forward $0^{\circ}$ and $30^{\circ}$ lenses (Karl Storz, Tuttlingen, Germany). Uterine distention was provided by using the continuous flow and pressure-controlled pump system after J. Hamou (Karl Storz). For the hysteroscopic surgical procedures done with the $5 \mathrm{~mm}$ instruments and the bipolar needle, we used saline solution as distension medium. For the monopolar resectoscopy, we used sorbitol solution as the distension medium. The electric generator used was an autocon II 400 (Karl Storz). The monopolar setting for cutting was $80-100 \mathrm{~W}$, and the bipolar setting for cutting at $40-60 \mathrm{~W}$ power. The procedure to follow and the choice of instrumentation used depend on the preclinical information provided. When the sonographic parameters showed a uterine length less than $9 \mathrm{~cm}$, an endometrial thickness less than $9 \mathrm{~mm}$, or one single lesion (polyp or myoma) less than $9 \mathrm{~mm}$, the procedure was started without any analgesic procedure and with the small-bored instruments.

In case major pathology was expected and the use of the resectoscope was scheduled, the patients underwent some kind of anesthesia (propofol sedation or spinal anesthesia). In this case the kind of anesthetic procedure was decided in the operating room by the anesthetist according the clinical characteristics of the patient and the estimated time of procedure by the hysteroscopist. In this case the patient was admitted in a recovery room with a nurse in constant surveillance during $6 \mathrm{~h}$ postoperative procedure.

The diagnostic hysteroscopy was performed following the vagino-cervical route under direct vision. After entering the uterine cavity, the tubal ostia were identified as the anatomical landmarks and a systematic examination was performed. Hysteroscopic findings were allocated either to "the uterine cavity lesions" or "the endometrial aspect." In the uterine cavity, lesion groups could be found: endometrial polyp, cervical polyp, myoma, cyst, malignant smooth muscle tumor, placenta rest, abortion debris, endometrial ossification, adhesions, congenital malformation, and lost IUD. In the endometrial aspect characterization group, we differentiated between functional, atrophic or thin endometrium, dysfunctional, endometritis, cystic atrophy, hyperplasia, polypoid, and carcinoma.

The hysteroscopic observation was documented, and an endometrial biopsy and/or the removal of the pathology were performed. The histopathological results were used as gold standard and compared with the hysteroscopic documented observation. The sensitivity, specificity, and predictive value of hysteroscopy were calculated.

\section{Results}

Four hundred nineteen women fulfilled the inclusion criteria. The average age was 54 years (range $24-87$ years), of which $43.9 \%$ were menopausal.
The referral cause was for the majority of patients (96.2\%) an abnormal results in the sonographic examination such as endometrial thickness, endometrial irregularity, endometrium heterogeneity, endometrium liquid, polyps, myomas, IUD, foreign body, and placental or fetal debris. Only $3.8 \%$ of patients had a normal sonographic exam, being in these patients the referral causes: one case of infertility, others of endometrial cells on cervix cytology, two cases of cervical polyps, five cases of post menopausal metrorrhagia, and six cases of menorrhagia.

We divided the hysteroscopic findings in two groups:

1. The uterine cavity lesions - those included 19 cases of uterine adhesions, 1 of which was associated with a myoma, another with a cervical and endometrial polyp, and 5 with endometrial polyps. Twelve cases of septate uterus were found, associated to endometrial cyst in 1 case, 3 cases to endometrial polyps, 1 to complex hyperplasia, and 2 to endometrial adenocarcinoma. A total of 247 endometrial polyps were diagnosed, 1 with adenocarcinoma, 8 were associated with cervical polyps, and 11 to myomas. There were 15 cervical polyps, 8 of which associated to endometrial polyps, and another to myoma and uterine adhesion. Submucous myomas were found in 42 patients. The other diagnostic lesions included three cases of endometrial cysts, six cases of abortion debris retention, one of placental retention, one case of malignant smooth muscle tissue, one case of residual endometrial ossification, and six of intrauterine retention of IUD, one of these associated to an endometrial polyp. The remainder 97 cases did not have any uterine lesion.

2. The endometrial aspect characterization -we detected 2 cases of endometrial carcinoma, 41 cases of endometrial hyperplasia, 45 cases of dysfunctional endometrium, 23 of polypoid endometrium, 4 cases of endometritis, and 6 cases of cystic atrophic endometrium. Functional endometrium was found in 109 cases, thin endometrium in 2 cases, and in 166, there was an atrophic endometrium. In 21 cases no endometrial biopsies were made. All of this included thin or atrophic endometrium in asymptomatic postmenopausal woman with concordant diagnosis of polyps on sonographic and hysteroscopic evaluation. In these patients only the polypectomy was performed.

When compared to histopathologic analysis as gold standard, hysteroscopy failed the diagnosis of the following uterine lesions: one case of myoma that was really a polyp, two cases considered without endometrial lesions that had polyps on histopathologic exam, and 2 polyps that were myomas after all (see Table 1). The hysteroscopy also failed in the endometrial characterization of the following cases: one complex hyperplasia (focal) wrongly classified as atrophic endometrium, two cases of dysfunctional endometrium, and 
Table 1 The uterine cavity lesions: hysteroscopic and histopathologic characterization

\begin{tabular}{lll}
\hline Uterine lesion & $\begin{array}{l}\text { Hysteroscopic } \\
\text { exam }\end{array}$ & $\begin{array}{l}\text { Histopathologic } \\
\text { exam }\end{array}$ \\
\hline Endometrial polyp & $\begin{array}{l}247^{\mathrm{a}} \\
(1 \text { carcinoma })\end{array}$ & $\begin{array}{c}248 \\
(1 \text { carcinoma })\end{array}$ \\
Cervical polyp & 15 & 15 \\
Myoma & $42^{\mathrm{b}}$ & 40 \\
Cyst & 4 & 3 \\
Malignant smooth muscle tumor & 1 & 1 \\
Placenta & 1 & 1 \\
Abortion first trimester debris & 6 & 6 \\
Bone (residual endometrial & 1 & 1 \\
$\quad$ ossification) & 19 & - \\
Endometrial adhesions & 12 & - \\
Septate uterus & 6 & - \\
IUD & $97^{\mathrm{c}}$ & $126^{\mathrm{d}}$ \\
No. of lesion & &
\end{tabular}

${ }^{a}$ FP-2 cases were myomas

${ }^{\mathrm{b}} \mathrm{FP}-1$ case was a polyp

${ }^{\mathrm{c}} \mathrm{FN}-2$ cases were polyps

${ }^{\mathrm{d}}$ Includes the 12 cases of isolated adhesions, 8 of isolated septate uterus, 5 of isolated lost IUD without other injuries associated, and still 1 case of cyst that had been destroyed and 4 of type 2 myomas which were not submitted to biopsy

two other of polypoid endometrium (Table 2). The hysteroscopic evaluation was characterized as functional endometrium, dysfunctional endometrium in 12 cases, polypoid endometrium in 4 , simple hyperplasia in 1 case, and complex hyperplasia in another. Two cases classified as focal complex hyperplasia in septate uterus were in the end endometrium adenocarcinomas. Considering the 22 false-positive diagnosis, these include 2 cases of focal hyperplasia that were atrophic endometrium, 5 cases of polypoid endometrium, 6 cases of dysfunctional endometrium, and 9 of hyperplasia that were all functional endometrium (see Tables 3 and 4).

Table 2 The endometrial aspect characterization by hysteroscopy and histopathologic exam

\begin{tabular}{lll}
\hline Endometrium characterization & $\begin{array}{l}\text { Hysteroscopic } \\
\text { exam }\end{array}$ & $\begin{array}{l}\text { Histopathologic } \\
\text { exam }\end{array}$ \\
\hline $\begin{array}{l}\text { Functional, atrophic, or thin } \\
\text { endometrium }\end{array}$ & 298 & $276+21$ no biopsy \\
$\begin{array}{l}\text { Dysfunctional } \\
\text { Endometritis }\end{array}$ & 45 & 53 \\
Cystic atrophy & 4 & 4 \\
Hyperplasia & 6 & 6 \\
Polypoid & 41 & 31 \\
Carcinoma & 23 & 24 \\
\hline
\end{tabular}

Table 3 Failure of endometrial diagnosis of endometrial characterization (false negative)

\begin{tabular}{lll}
\hline Hysteroscopic exam & Histopathologic exam & False negative \\
\hline Hyperplasia & Carcinoma & 2 \\
Functional & Polypoid & 4 \\
Functional & Hyperplasia (1 simple, & 2 \\
& $\quad$ complex) & 12 \\
Functional & Dysfunctional & 2 \\
Atrophic & Dysfunctional & 2 \\
Atrophic & Polypoid & 1 \\
Atrophic & Complex hyperplasia & \\
\hline
\end{tabular}

Considering the diagnostic accuracy of hysteroscopy in the evaluation of intra-cavity lesions, the sensitivity, specificity, positive and negative predictive values were respectively $99.3 \%, 97.7 \%, 98.9 \%$, and $98.5 \%$. The values of the same parameters regarding the characterization of endometrium were as follows: $79.8 \%, 91.97 \%, 81.8 \%$, and $90.97 \%$. The diagnostic accuracy was $98.8 \%$ for endometrial lesions diagnosis and $88.8 \%$ for endometrial characterization.

The incidence of endometrial adenocarcinoma was $1.2 \%$, and the sensitivity and specificity of hysteroscopy were respectively $60 \%$ and $99.5 \%$, with a diagnostic accuracy of $99.5 \%$. The incidence of endometrial hyperplasia was $9.8 \%$. The hysteroscopy had a sensibility of $90 \%$ and a specificity of $97 \%$ for the diagnosis of this pathology, and the diagnostic accuracy was $64 \%$.

The complication rate was $3.3 \%$, including 2 cases of postoperative hemorrhage that were inpatient for 24$\mathrm{h}$ surveillance and were discharged after that and 12 cases of some kind of perforation or false route. Only half of these patients stood for 24-h inpatient surveillance and were dismissed with no other complication, except one case of uterine perforation during a myomectomy of a $4-\mathrm{cm}$ myoma in a postmenopausal woman, which became the most serious complication because the resectoscope hook entered in the abdominal cavity and so laparotomy was performed to exclude abdominal injury and hysterectomy was performed at the same time.

The five endometrial carcinomas (one in a polyp lesion) were submitted to a gynecology oncologic committee

Table 4 Failure of endometrial diagnosis of endometrial characterization (false positive)

\begin{tabular}{lll}
\hline Hysteroscopic exam & Histopathologic exam & False positive \\
\hline Hyperplasia & Functional & 9 \\
Polypoid & Functional & 5 \\
Dysfunctional & Functional & 6 \\
Hyperplasia & Atrophic & 2 \\
\hline
\end{tabular}


which selected the final treatment, and all cases submitted to hysterectomy: two cases were endometrioid adenocarcinoma in situ (stage T1is) and three cases were welldifferentiated, invasive endometrioid adenocarcinomas with less than half myometrium invasion, i.e., T1N0M0.

\section{Discussion}

Transvaginal sonography is a valuable method to identify women at risk for endometrial disease, not only by measuring endometrium thickness but also by accessing focal abnormalities within the endometrial cavity. But, its value is limited in the endometrial characterization because the image of endometrium is given in a gray scale which makes interpretation difficult and less accurate, and also because although in post menopausal women the presence of thick endometrium (i.e., more than $5 \mathrm{~mm}$ ) may predict some kind of pathology [1-3], the exact lesion cannot most of times be discriminated. Transvaginal ultrasound fails to differentiate intrauterine abnormalities (i.e., myomas, polyps, hyperplasia, etc.), so having a low diagnostic sensitivity ranging from $76 \%$ to $96 \%[4,5]$. Visualization of the endometrial echo or endomyometrial complex may also be limited by the uterine position, myometrial lesions that distort endometrial line, and by the resolution of the imaging technology. The accuracy of this modality is also related to the timing of the menstrual period or menopausal status. It is also notable that polyps and myomas less than $1 \mathrm{~cm}$ in diameter cannot be detected by transvaginal sonography [6].

Hysteroscopic inspection of uterine cavity is a simple, outpatient and well-accepted method for investigation of intrauterine pathology [7]. The direct visualization in vivo, real-time, real-color, hydrated, well-illuminated, and augmented vision of the uterine cavity make this diagnostic tool very accurate to detect minute focal endometrial pathology and small lesions otherwise not possible, complemented to the ability of performing guided direct biopsies and treatment on the same diagnostic procedure $[8,9]$.

Hysteroscopic examination may predict endometrial lesions with a good accuracy as well as endometrial aspect characterization, adopting a nomenclature similar to that used by the pathologist. This approach makes correlation between hysteroscopic findings and histopathologic results easier, as well as the dialogue between others investigators; the use of a universal language is the best way to achieve concordant and consistent results.

Comparing our results with other studies, we conclude that diagnostic power of hysteroscopy is very different among the various studies in medical literature (see Table 5). Various factors are implicated in these different results, including the hysteroscopist experience, quality of equipment, distension source, quality of the endometrial sampling, focus population including (pre- or postmenopausal), and patient selection (clinical symptoms, sonography suspected) [10].

The accuracy of hysteroscopy to diagnose uterine lesions is better than that of endometrial characterization $(98.8 \%$ versus $88.8 \%$ ). The false diagnoses were lower and include: one case of hysteroscopic diagnosis of myoma that was a polyp, a fibrous polyp with a very round shape may macroscopically simulate a polyp, and two cases of polyps that were myomas on histopathologic exam; myomas type 1 or 2 with a secretor endometrium covering its surface;

Table 5 Comparing studies in accessing sensitivity and specificity of hysteroscopy for diagnose endometrial pathology

\begin{tabular}{lllllc}
\hline Author (reference) & Year & No. of women & Hormonal state & Focus & Sensitivity \\
\hline Gezer et al. [20] & 2004 & 385 & Pre/postmenopausal & AUB/polyps & 83.9 \\
Gezer et al. [20] & 2004 & 385 & Pre/postmenopausal & AUB/myomas & 63.9 \\
Feng and Li [4] & 2002 & 112 & Pre/postmenopausal & PMM/abnormal US & 90 \\
Tinelli et al. [21] & 2008 & 752 & Postmenopausal & PMM & 92.3 \\
Angioni et al. [22] & 2008 & 319 & Postmenopausal & PMM/polyps & 98 \\
Angioni et al. [22] & 2008 & 319 & Postmenopausal & PMM/myomas & 100 \\
Loverro et al. [6] & 1999 & 106 & Postmenopausal & PMM (no HRT) & 97.4 \\
Sousa et al. [23] & 2001 & 200 & Postmenopausal & PMM & 97 \\
Cordeiro et al. [24] & 2009 & 245 & Postmenopausal & Abnormal TUS/benign polyps & 97.5 \\
Cordeiro et al. [24] & 2009 & 245 & Postmenopausal & Abnormal TUS/adenocarcinoma & 98.7 \\
Antunes & 2010 & 419 & Pre/postmenopausal & Abnormal TUS or clinics/ & 94.1 \\
Antunes & 2010 & 419 & Pre/postmenopausal & Abnormal TUS or clinics/ & 99.3 \\
& & & & endometrium characterization & 79.3 \\
\end{tabular}

$A U B$ abnormal uterine bleeding, $P M M$ postmenopausal metrorrhagia, TUS transvaginal ultrasound 
and the two false negative include two focal thicker lesions interpreted as dysfunctional endometrium that were polyps on histopathologic exam.

The false diagnosis on endometrium characterization is a concern, particularly the false negative; 12 cases of dysfunctional endometrium were misdiagnosed as functional endometrium. Dysfunctional endometrium traduces a discordant maturation between endometrium and the hormonal cycle, or a focal discordance with focal areas in various phases of endometrial cycle at the same time. The estrogen and progesterone receptors' distribution on the endometrium layer is irregular, varying from one region to one other, with the day of the cycle and is dependent on the presence of "accidents" on the endometrial cavity like myomas, polyps, and septate [11]. Those lesions may be very subtle and we may not interpret them; in these cases, the use of a colorant might help us. Only seriated biopsies can help us to diagnose these subtle lesions. The above commentary is extensive to the other cases of "innocent" endometrium (functional or atrophic) and that the biopsy revealed polypoid or hyperplasic endometrium [12-14].

We found a higher incidence of carcinomas on septate uterus $16.7 \%$ versus $1.2 \%$ on the total studied population. These uteri have a greater endometrial surface and a congenital intra-cavity accident, so might be more susceptible to endometrial proliferative disease including carcinoma. This must be confirmed with more investigation.

The two false negative (for carcinoma) occurred with septate uterus in two postmenopausal patients. In one case, the hysteroscopic exam revealed complex hyperplasia and the histopathologic exam revealed well-differentiated, invasive adenocarcinoma (T1N0M0); the other case was a hysteroscopic diagnosis of simple focal hyperplasia, and the biopsy revealed complex atypical hyperplasia with focus of adenocarcinoma. After hysterectomy the histopathologic examination showed in an area of $3 \mathrm{~mm}$ (corresponding to the biopsied area) in situ endometrioid adenocarcinoma. Hysteroscopic guided biopsy permitted the correct histopathologic diagnose.

It is understood that preoperative blind biopsies specimens are insufficient for diagnosis in women with intrauterine lesions which include neoplasias [15]. Furthermore, investigators have reported that hysteroscopy had failed to detect endometrial adenocarcinoma and stromal cancer [16], also a well-recognized complex hyperplasia and has a very similar hysteroscopic image to carcinoma $[17,18]$. Combined hysteroscopy and biopsy leads to almost $100 \%$ accuracy in diagnosis of carcinoma and its precursors [18]. Hysteroscopists, whatever their experience, should not ever forget this complementary procedure, the hysteroscopic guided biopsy whatever for benign or malignant pathology [19].
We recommend that all patients should have a transvaginal sonographic exam performed previously to the hysteroscopy, the sonographic findings plus the clinical data permit to select the correct hysteroscopic material (2, 3 , or 4-mm scopes) and well planning the exam (with or without cervical preparation, with or without anesthesia). Hysteroscopy exam should include a detailed inspection for 15-20 min of the total uterine cavity and several biopsies of every suspicious lesion and should include all endometrial layers. We recommend the use of scissors to catch a sufficiently profound and large specimen, instead of using the biopsy forceps alone. The specimen should be placed directly on the formol container to avoid material fragmentation. Lastly and very important is the continuous dialogue with the pathologist and constant auto critics comparing every hysteroscopic findings with the histopathologic exam, and is from this reflection that we may offer the patient and our colleges the best we can.

\section{Conclusion}

The hysteroscopy allows direct visualization of uterine cavity, and this particularity confers it a high diagnostic acuity, that associated to the possibility of simultaneous treatment or biopsy procedures gives it an irreplaceable value in the diagnosis and treatment of intrauterine diseases.

Conflict of interest No payment or support was received in kind for any aspect of the submitted work (including but not limited to grants, data monitoring board, study design, manuscript preparation, statistical analysis, etc.). There have been no financial relationships (regardless of amount of compensation) with any entities that have an interest related to the submitted work. There have been no financial associations or interests (personal, professional, political, institutional, and religious or others) that a reasonable reader would want to know about in relation to the submitted work. The above declaration is signed by the author.

\section{References}

1. Smith-Bindman R, Kerlikowske K, Feldstein VA et al (1998) Endovaginal ultrasound to exclude endometrial cancer and other endometrial abnormalities. J Am Med Assoc 280:15101517

2. Bree RL, Carlos R (1995) US for postmenopausal bleeding consensus development and patient-centered outcomes. Radiology 222:595-598

3. Karlsson B, Granberg S, Wikland M et al (1995) Transvaginal ultrasonography of the endometrium in woman with postmenopausal bleeding - a Nordic multicenter study. Am J Obstet Gynecol 172:1488-1494

4. Feng L, Li D (2002) Evaluation of intrauterine disorders by hysteroscopy and transvaginal sonography. Gynecol Endosc 11:401-404 
5. Gibbs Henson J, Hawkins K (2004) A retrospective analysis of the role of transvaginal sonography in the evaluation of patients with abnormal postmenopausal bleeding. BMUS J 12(4):218-221

6. Loverro G, Bettochi S, Cormio G, Nicolardi V et al (1999) Transvaginal sonography and hysteroscopy in postmenopausal uterine bleeding. Maturitas 33(2):139-144

7. Paschopoulos EB, ParasKevaidiis E, Stefanidis K et al (1997) Vaginoscopy approach to outpatient hysteroscopy. J Am Assoc Gynecol Laparosc 4:13-15

8. Pasqualotto EB, Margossian H, Price LL et al (2000) Accuracy of preoperative diagnostic tools and outcome of hysteroscopic management of menstrual dysfunction. J Am Assoc Gynecol Laparosc 7:201-209

9. Pal L, Lapensee L, Toth TL et al (1996) Comparison of office hysteroscopy, transvaginal ultrasonography in the diagnosis of endometrial abnormalities. Obstet Gynecol 87:345-349

10. Bruno E, Gama CR (2003) Hipertrofia endometrial. In: Crispi CP, Oliveira FMM, Errico G, Damian Junior JC (eds) Tratado de Videoendoscopia Ginecologica. Atheneu, São Paulo, pp 1021-1032

11. Miyahira H (1995) Analise crítica do diagnostic histeroscopico endometrial (1995) In Tese de Doutorado em Medicina (Ginecologia), UFRJ:10-30

12. Silveira LP (1998) Análise do valor preditivo do diagnóstico histeroscópico de endométrio hipertrófico. In Tese de mestrado em Medicina (Ginecologia), UFR:15-22

13. Fay TN, Khanen N, Hosking D (1999) Out-patient hysteroscopy in asymptomatic postmenopausal women. Climacteric 2:263-267

14. Clark TJ, Voit D, Gupta JK et al (2002) Accuracy of hysteroscopy in the diagnosis of endometrial cancer and hyperplasia: a systematic quantitative review. J Am Med Assoc 288(13):1610-1621

15. Kent AS, Haines P, Manners TB et al (1996) Blind endometrial biopsies: insufficient for diagnosis in woman with intra-uterine pathology. Gynecol Endosc 7:273-278
16. Colafranceschi M, Bettochi S, Mencaglia L et al (1996) Missed hysteroscopic detection of uterine carcinoma before endometrial resection: report of three cases. Gynecol Oncol 62(2):298300

17. Mencaglia L (1995) Hysteroscopy and adenocarcinoma. Obstet Gynecol Clin North Am 22(3):573-579

18. Mencaglia L, Valle RF, Perino A, Guilard G (1990) Endometrial carcinoma and its precursors: early detection and treatment. Int $\mathrm{J}$ Gynecol Obstet 31:107-116

19. Gasparri F, Scarselli G, Mencaglia L (1984) Studio pilota periáttuazione dello screening per il carcinoma dell'endométrio. Oncol Gynecol 3:50

20. Gezer A, Saar A, Demirkiran F, Benian A et al (2004) The efficacy of hysteroscopy for endometrial pathology: the experience of a university clinic on diagnostic accuracy and the comparison with the other methods. Gynecol Surg 1 (4):227-230

21. Tinelli R, Tinelli FG, Cicinelli E, Malvasi A, Tinelli A (2008) The role of hysteroscopy with eye-directed biopsy in postmenopausal woman with uterine bleeding and endometrial atrophy. Menopause 15(4 Pt 1):737-742

22. Angioni S, Loddo A, Milano F, Piras B et al (2008) Detection of benign intracavitary lesions in postmenopausal woman with abnormal uterine bleeding: a prospective comparative study on outpatient hysteroscopy and blind biopsy. J Minim Invasive Gynecol 15(1):87-91

23. Sousa R, Silvestre M, Sousa LA, Falcão F et al (2001) Transvaginal ultrasonography and hysteroscopy in post menopausal bleeding: a prospective study. Acta Obstet Gynecol Scand 80:856-862

24. Cordeiro A, Condeço R, Leitão C et al (2009) Office hysteroscopy after ultrasonographic diagnosis of thickened endometrium in postmenopausal patients. Gynecol Surg 6:317-322 